\title{
ANÁLISIS BACTERIOLÓGICO DE SUPERFICIES INERTES Y SENSIBILIDAD ANTIBIÓTICA EN EL SERVICIO DE CIRUGÍA GENERAL DEL HOSPITAL REGIONAL DE ICA
}

\author{
BACTERIOLOGICAL ANALYSIS OF INERT SURFACES AND ANTIBIOTIC \\ SENSITIVITY IN THE GENERAL SURGERY SERVICE OF THE REGIONAL \\ HOSPITAL OF ICA
}

\author{
Leveau-Bartra Harry ${ }^{1, a}$, Leveau-Bartra Orison ${ }^{2, b}$, Arizola-Aguado Alicia $^{1, c}$ \\ 1. Universidad Particular San Juan Bautista. Filial-Ica. \\ 2. Universidad Nacional de Ucayali. \\ a. Cirujano General. \\ b. Médico Patólogo Clínico
}

doi: https://doi.org/10.35563/rmp.v8i2.5

\section{Correspondencia:}

Leveau-Bartra Harry.

Número de celular: +51956608888

Correo Electrónico:

kahaisail4@hotmail.com

\section{Contribuciones De Autoría:}

LBH, LBO, AAA, participaron en el diseño del estudio, el análisis de los datos, revisaron críticamente el artículo y aprobaron la versión final.

Conflicto De Intereses: No declarados.

Financiamiento: Autofinanciado.

\section{Como Citar}

Leveau Bartra Harry, Leveau Bartra Orinson, Arizola Aguado Alicia. Análisis bacteriológico de superficies inertes y sensibilidad antibiótica en el servicio de cirugía general del Hospital Regional de Ica. Rev méd panacea. 2019; 8(2): 73-77. doi: https://doi.org/10.35563/rmp.v8i2.274

Recibido: 17 - 03 - 2019

Aceptado: 20 - 05 - 2019

Publicado: 12 - 05 - 2019

\section{RESUMEN}

Objetivo: Identificar las bacterias presentes en superficies inertes del área de cirugía y conocer su respectiva sensibilidad antibiótica según corresponda. Materiales y métodos: Estudio observacional, descriptivo, transversal, prospectivo. Investigación para identificar microorganismos patógenos en superficies inanimadas del Hospital Regional de Ica. Se procedió a las tomas de muestra humedeciendo el hisopo en el caldo cerebro corazón y luego sembrado en agar sangre $5 \%$, agar Mac Conkey y agar manitol salado, incubándolos durante 24 horas a $37^{\circ} \mathrm{C}$, tinción de Gram, pruebas de catalasa y oxidasa. Se realizó la primera lectura dentro de las 24 horas. Resultados: Estafilococus coagulasa negativo se aislaron en el lavadero, coche de medicación, mesa de comer, coche de curación de cirugía B y mesa de comer. Bacillus sp. se aislaron en pared y mesa de comer de Cirugía General. Staphylococsus aureus se aislaron en coche de medicación y coche de curación. Pseudomonas sp. Se aisló en mesa de comer de Cirugía General. El Staphylococcus aureus es resistente a la mayoría de antibióticos que usualmente se utiliza en el departamento de cirugía general del Hospital Regional de Ica. La Psudomona Sp. es resistente a antibióticos que usualmente se utiliza en el servicio de cirugía general, aunque es sensible a algunos antibióticos utilizados en este servicio. Conclusiones: Se encontraron gérmenes en superficies inanimadas que están en intimo contacto con pacientes del departamento de cirugía del Hospital Regional de Ica que pone en riesgo a contraer infecciones intrahospitalarias. El Staphylococcus aureus presenta mayor resistencia antibiótica que la Pseudomona Sp.

Palabras clave: Gérmenes superficies inertes.

\section{ABSTRACT}

Objective: To identify the bacteria present in inert surfaces of the surgery area and to know their respective antibiotic sensitivity as appropriate. Materials and methods: Observational, descriptive, cross-sectional, prospective study. Research to identify pathogenic microorganisms on inanimate surfaces of the Regional Hospital of Ica. The samples were taken by moistening the swab in the brain heart broth and then seeded on 5\% blood agar, Mac Conkey agar and salted mannitol agar, incubating them for 24 hours at $37^{\circ} \mathrm{C}$, Gram stain, catalase and oxidase tests. The first reading was made within 24 hours. Results: Staphylococcus coagulase negative were isolated in the laundry, medication car, eating table, surgery B healing car and eating table. Bacillus sp. They were isolated in the wall and table of eating of General Surgery. Staphylococcus aureus were isolated in medication car and healing car. Pseudomonas sp. It was isolated on a General Surgery table. Staphylococcus aureus is resistant to most antibiotics that is usually used in the general surgery service of the Regional Hospital of Ica. And Psudomona Sp. Is resistant to antibiotics that is usually used in the general surgery service, although it is sensitive to some antibiotics used in this service. Conclusions: Germs were found on inanimate surfaces that are in intimate contact with patients of the surgical departament of the Regional Hospital of Ica, which puts them at risk of contracting nosocomial infections. Staphylococcus aureus has greater antibiotic resistance than Pseudomona Sp.

Keywords: Germs inert surfaces. 


\section{INTRODUCCIÓN}

Las infecciones nosocomiales se definen como las que ocurren durante la hospitalización de un paciente, no están presentes en la hospitalización o durante el período de incubación y son un problema continuo en los hospitales de todo el mundo (1).

Esto se debe, entre otros factores, a la alta frecuencia de pacientes con trastornos inmunitarios, a la aparición de microbios resistentes, a la mayor complejidad de las intervenciones realizadas y a la ejecución de procedimientos invasivos. Las infecciones adquiridas en el hospital son una de las principales causas del aumento de la mortalidad y la morbilidad en pacientes hospitalizados, y una carga significativa para los pacientes y los sistemas de salud.

Durante más de 20 años se ha considerado que la fuente más importante de la enfermedad nosocomial es de tipo endógeno, pero se evalúa que el $20-40 \%$ de las contaminaciones se adquieren de manera transversal a partir de diferentes pacientes o personal y el $20 \%$ de la atmósfera. La contaminación de las superficies alrededor de los pacientes es un factor de discusión en el control de las enfermedades nosocomiales. Hay algunos factores a considerar: a) la capacidad del microorganismo de sobrevivir en superficies inertes; b) lo difícil que resulta de eliminar estos microorganismos y c) la ausencia de pautas de control de ordenación de la superficie para gérmenes intranosocomiales (2).

Un estudio de incidencia desarrollada con la subvención de la OMS en 55 nosocomios de 14 países típicos de 4 regiones que pertenecen a la OM (Asia Sudoriental, Mediterráneo oriental, Pacífico occidental y Europa) demostraron que el $8.7 \%$ de enfermos internados presentaron infecciones intrahospitalarias (1).

En Europa la tasa de infecciones nosocomiales está alrededor del $5 \%$ y en el Perú varía entre 3,7 y 7,5\% dependiendo del tipo de institución hospitalaria (3).

Los ambientes hospitalarios albergan pacientes con diferentes patologías algunas no infecciosas y otras infecciosas y son estas últimas que muchas veces son fuente de contagio a otros pacientes o al mismo personal sanitario, las que llegan al huésped por distintas vías, sea esta vía área (Gotitas de Flûgge) o suspensiones aéreas, contacto directo a través de manos 0 , a través de vectores (insectos). En el servicio se cirugía general del Hospital Regional de Ica de reciente construcción se tiene 40 camas con alto porcentaje de ocupación por la gran demanda hospitalaria. Las patologías más frecuentes motivos de hospitalización en este servicio son pie diabético complicado, pos operados de apendicitis aguda y pos operado de colecistectomía, entre otras de menos frecuencia. Las infecciones intrahospitalarias no son una excepción en este servicio los datos al respecto son subvaluados por la deficiente información que cuenta este nosocomio, lo que hace que muchos diagnósticos no son registrados adecuadamente.

El Hospital Regional de Ica es un hospital de referencia importante para la región y además es docente albergando a alumnos de carreras de salud de las diferentes Universidades de la zona. Por lo que debe considerarse el estudio realizado por Catalán, I. (4) en España donde concluye que los hospitales de mayor tamaño y docentes presentaron una tasa de Neumonía asociada a ventilación mecánica superior a los de menor tamaño y no docentes.

De allí la importancia de esta investigación que identifica gérmenes patógenos que provocan alta letalidad y que se encuentran en el ambiente, en superficies inanimadas, en el propio paciente y personal sanitario. Así mismo, se determinó la sensibilidad antibiótica de los principales gérmenes patógenas. La investigación solo se limitó a identificar los principales gérmenes en las superficies inanimadas recomendando en otra oportunidad ampliar el área de análisis de los mismos. Al respecto, en 1978 Cozanitis y cols., describen la contaminación bacteriana de teléfonos en cuidados intensivos. (Citado en: Muñoz J. (5) et. al. 2012 p2.). Del mismo modo cerca del 42 por ciento de teléfonos celulares de uso por los servidores de salud se encuentran contaminados con microorganismos potencialmente infectantes. (citado en llanos 2017) (3).

\section{MATERIALES Y MÉTODOS \\ Tipo de investigación}

Estudio observacional, transversal, retrospectiva y descriptiva.

\section{Nivel y Diseño de estudio}

Nivel descriptivo

Diseño Representado como:

$$
\begin{aligned}
& \text { Donde: } \\
& \text { M = Muestra } \\
& \text { O1 = Observación } \\
& \text { Materiales }
\end{aligned}
$$

\section{Materiales}

- Hisopos de algodón estériles

- Guantes descartables

- $\quad$ Tubos de ensayo de 13×100 mm con tapa rosca

- $\quad$ Asas estériles

- Mascarillas descartables

- Protector de cabello

- Plumón marcador

- Cooler

- Caldo de encéfalo corazón

- Agar Mac Conkey

- $\quad$ Agar Sangre 5\%

- Agar Manitol con sal

- Agar Mueller hinton

- Discos de sensibilidad

\section{Población}

Áreas inertes del departamento de cirugía del Hospital Regional de Ica.

\section{Muestra}

Se muestrearon 16 ambientes del área de hospitalización de Cirugía, 8 en Cirugía A y 8 en Cirugía B, dentro de los cuales se incluyeron: lavaderos (2), coche de medicación 
(1), coche de curación, paredes (2) y mesas de comer (2),

\section{Muestreo}

Probabilístico al azar simple.

\section{Unidad de análisis}

Superficie inerte

\section{Procedimiento}

- Humedecer el hisopo en el caldo cerebro corazón y bajo preseión suave sobre la superficie interna del tubo con movimientos de rotación para eliminar los sobrantes del caldo.

- Con hisopo bajo inclinación sobre $30^{\circ}$, frotar 4 veces en direcciones opuestas una superficie 10 centímetros x 10 centímetros.

- Poner el hisopo dentro del tubo que contiene una solución diluyente.

- Transportar las muestras al laboratorio de microbiología, y se sembró en agar sangre 5\%, agar Mac Conkey y agar manitol salado, incubándolos durante 24 horas a $37^{\circ} \mathrm{C}$.

- Se hicieron tinción de Gram, pruebas de catalasa y oxidasa, procediéndose a la identificación por pruebas bioquímicas convencionales y se les realizó antibiograma por el método de disco en difusión.

Se realizó la primera lectura dentro de las 24 horas a fin de identificar los principales microorganismos: Estafilococus coagulasa negativo, Bacillus sp, Staphylococus aureus y Pseudomonas sp.

\section{Hipótesis}

No aplica

Variables

Variable de estudio

Bacterias en superficies inertes

Variable de caracterización

Tipos de bacterias

Superficies inertes

Sensibilidad antibiótica

\section{RESULTADOS}

Tabla 1: Principales gérmenes identificados en superficies inertes del servicio de Cirugía del Hospital Regional de Ica noviembre del 2018.

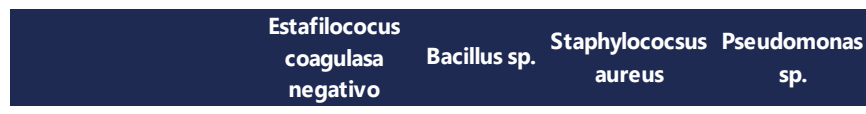

Lavaderos

Coche de medicación

Mesa de comedor

Coche de curación

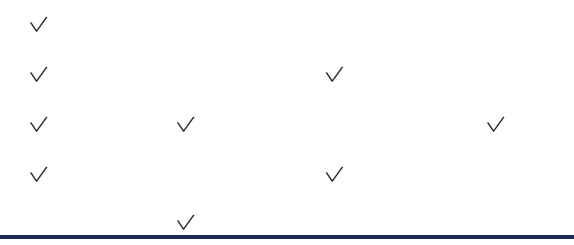

Fuente: Hospital Regional de Ica

Resultado: Estafilococus coagulasa negativo se aislaron en el lavadero, coche de medicación, mesa de comer, coche de curación de cirugía $B$ y mesa de comer de Cirugía A. Bacillus sp. Se aislaron en pared y mesa de comer de Cirugía General. Staphylococsus aureus se aislaron en coche de medicación y coche de curación de cirugía A. Pseudomonas sp. Se aisló en mesa de comer de Cirugía General.

Tabla 2: Sensibilidad antibiótica de los principales gérmenes patógenos identificados en superficies inertes Principales del servicio de Cirugía del Hospital Regional de Ica noviembre del 2018.

\begin{tabular}{|c|c|c|}
\hline Sensible & Intermedio & Resistente \\
\hline Vancomicina & & Oxacilina \\
\hline \multirow[t]{6}{*}{ Teicoplanina } & & Sulfatrimetropir \\
\hline & & Penicilina \\
\hline & & Eritromicina \\
\hline & & Clindamicina \\
\hline & & Levofloxacino \\
\hline & & Tetraciclina \\
\hline
\end{tabular}

\section{Fuente: Hospital Regional de Ica}

Resultado: Uno de los gérmenes patógeno más comunes como es el Staphylococcus aureus es resistente a la mayoría de antibióticos que usualmente se utiliza en el departamento de cirugía general del Hospital Regional de Ica.

Tabla 3: Sensibilidad antibiótica de los principales gérmenes patógenos identificados en superficies inertes Principales del servicio de Cirugía del Hospital Regional de Ica noviembre del 2018.

\section{BACILOS GRAM NEGATIVOS: PSEUDOMONA Sp

Sensible Intermedio Resistente

Cefotaxima

Cefuroxima

Ampicilina

Ceftazidima

Ampicilina/Sulbactam

Levofloxacino

Cefalotina

Meropenem

Cefoperazona/Sulbactam

Piperaciclina/Tazobactam

\section{Fuente: Hospital Regional de Ica}

Resultado: Uno de los gérmenes patógeno más comunes como es la Psudomona Sp. es resistente a antibióticos que usualmente se utiliza en el departamento de cirugía general del Hospital Regional de Ica, quedando aún algunos antibióticos al que son sensibles. 


\section{DISCUSIÓN}

Muchos factores contribuyen a las infecciones nosocomiales. Dependiendo de la sensibilidad del paciente: edad, sexo, enfermedad subyacente, estado inmune. Medio ambiente: plantas físicas, personal hospitalario, planes de visitas. Tratamiento institucional: inmunosupresores, antibióticos, técnicas invasivas, reconociendo dos fuentes de contagio: Humanos y No humanos dentro de estos último los inertes, ambientales y soluciones (6)

Actualmente queda establecido que todo lo que está alrededor del paciente debe estar exenta de gérmenes para evitar infecciones nosocomiales. Podemos decir que en todo lo que está seco y limpio no se desarrollan microorganismos que provocan infecciones, es lo que se considera un principio (7)

En la investigación como muestra la tabla $N^{\circ} 1$ se encontraron microorganismos patógenos en superficies inanimadas como lavaderos, coche de medicación, mesa de comedor, coche de curación, paredes, que son estructuras muy cercanas a los pacientes hospitalizados en este servicio y considerando que todo paciente pos operado es un paciente con bajas defensas sobre todo aquellos con comorbilidades como la diabetes mellitus tipo 2, es que dichos pacientes se encuentran en riesgo de infecciones intrahospitalarias adquiridas a partir de estas estructuras inanimadas que llegarían a ellos a través de manos del personal sanitario o a través del aire al ser removidos sin previo uso de desinfectantes. Existen estudios al respecto como lo realizado por Llanos en el Hospital Arzobispo Loayza de Lima donde encuentra que 111 de 124 (91,9\%) estetoscopios estudiados estuvieron contaminados con bacterias patógenas, tanto Gram positivas como Gram negativas, las que con una alta frecuencia son resistentes a múltiples antibióticos.3 Además, Paz-Montes A, Fuenmayor-Boscán A. (8) en su estudio sobre riesgo bacteriano relacionado con utilización de teléfonos celulares en el servicio de laboratorio de Maracaibo-Venezuela, concluye que en $83 \%$ de los teléfonos se evidenció contaminación bacteriana y en $29 \%$ se identificó agentes con potencial patogénico definido, predominando Enterococcus spp., anaerobios estrictos, Staphylococcus aureus y enterobacterias.

Los gérmenes patógenos más frecuentes encontrados en este estudio son:

Estafilococus coagulasa negativo Bacillus sp. Staphylococsus aureus Pseudomonas sp. Algunos de estos gérmenes fueron encontrados en la Infecciones
Intrahospitalarias en el Hospital Goyeneche III-1 de Arequipa, 2012-2016, como agentes etiológicos: P. aeruginosa (20.22\%), A. baumannii (16.85\%), S. coagulasa negativos (15.73\%), S. aureus (12.36\%), E. coli (10.11\%), K. pneumoniae (4.49\%) y en hongos a Candida sp. (5.62\%) (9). Es de poner en consideración que según Garcia De la Cruz, Y., Romero Berrocal, R. (10). en su estudio para determinar el efecto de dos desinfectantes de uso hospitalario sobre el crecimiento In vitro de Staphylococcus aureus y Escherichia coli, concluyen que los desinfectantes Hipoclorito de sodio y Amonio cuaternario no tienen efecto significativo sobre el crecimiento In vitro de S. aureus y E. coli.

Así mismo, el ozono debido a su alto potencial oxidante, es capaz de eliminar toda clase de bacteria, tanto en el aire como en alguna superficie. El nivel de desinfección dependerá de la concentración del ozono en un ambiente, el tipo de bacteria y el tiempo de exposición (11).

Nunura, determina que los patógenos aislados prevalentes en el Servicio de Cuidados Críticos en una búsqueda bibliográfica de las principales bases de datos son: la E.Coli con un $18 \%$, la Pseudomona aeruginosa y del Acinetobacter baumannii con un 13\% (12). Es así como Rivera de la Torre, D. concluye en su estudio que se debe detectar las superficies con mayor contacto manual en las habitaciones hospitalarias, evaluar la eficacia del proceso de limpieza y desinfección, sin olvidar de crear conciencia sobre la importancia de un entrono limpio y saludable por medio de difusión de información (13).

En la tabla $\mathrm{N}^{\circ} 2$ se determinó una alta resistencia antibiótica para el germen Staphylococcus aureus que está involucrado en muchas infecciones intrahospitalarias sobre todo neumonía intrahospitalaria, por lo que su erradicación en los ambientes de cirugía es necesaria.

Así mismo en la tabla $\mathrm{N}^{\circ} 3$ se precisa que la Pseudoma Sp también presenta resistencia antibiótica importante que requiere ser tomado en cuenta al momento de elegir antibióticos en forma empírica hasta esperar los resultados de sensibilidad antibiótica.

\section{CONCLUSIONES}

Se encontraron gérmenes en superficies inanimadas que están en intimo contacto con pacientes del servicio de cirugía que pone en riesgo a contraer infecciones intrahospitalarias.

Existe alta resistencia antibiótica a gérmenes patógenos como Staphylococcus aureus y Pseudomona Sp. 


\section{REFERENCIAS BIBLIOGRÁFICAS}

1. Promoción de la calidad guía de buenas prácticas prevención y control de la infección nosocomial. Salud Madrid.

2. López Cerero, L. Papel del ambiente hospitalario y los equipamientos en la transmisión de las infecciones nosocomiales. Unidad de Gestión Clínica de Enfermedades Infecciosas y Microbiología Clínica, Hospital Universitario Virgen Macarena, Sevilla, España. Enferm Infecc Microbiol Clin. 2014;32(7):459-464

3. Llanos-Cuentas A. Transmisión de infecciones nosocomiales por el personal de salud. Rev Med Hered. 2016; 27:73-74.

4. Catalán Gómez, I. ¿Influye la estructura hospitalaria en la etiología de la neumonía asociada a ventilación mecánica? Diferencias en la Etiología de la Neumonía Asociada a Ventilación Mecánica según la Estructura Hospitalaria. España. 2017

5. Muñoz Escobedo, J; Varela Castillo, L; Chávez Romero, P; Becerra Sánchez, A; Moreno García, M. Bacterias patógenas aisladas de teléfonos celulares del personal y alumnos de la Clínica Multidisciplinaria (CLIMUZAC) de la unidad Académica de Odontología de la UAZ Archivos Venezolanos de Farmacología y Terapéutica, vol. 31, núm. 2, abril-junio, 2012, pp. 23-31

6. Macedo, M., Blanco, J. Infecciones hospitalarias. Disponible en:

www.higiene.edu.uy/cefa/2008/infeccioneshospitalari as.pdf
7. Comité de Prevención y Control de Infecciones de adquisición Hospitalaria HZTW. Guía N 3: Manual Integral de Procedimientos de Higiene Hospitalaria. hospital Zonal de Trelew "Adolfo Margara". 2017

8. Paz-Montes A, Fuenmayor-Boscán A. Riesgo microbiológico asociado al uso de teléfonos móviles en laboratorios clínicos hospitalarios de Maracaibo-Venezuela. Rev. Kasmera 43(2): 148 - 157, Julio-diciembre 2015

9. Ramos Infantes F. Infecciones intrahospitalarias, resistencia antimicrobiana y factores de riesgo en pacientes de la unidad de cuidados intensivos del Hospital Goyeneche III-1 de Arequipa, 2012-2016

10. Garcia De la Cruz, Y., Romero Berrocal, R. Efecto de dos desinfectantes de uso hospitalario sobre el crecimiento in vitro de Staphylococcus aureus y Escherichia coli. Huancayo 2018.

11. Gonzales Vásquez C. Diseño e implementación de un sistema antiséptico aplicado a la desinfección de habitaciones en hospitales mediante el uso del ozono. Lima 2014

12. Nunura Caldas M. Prevalencia de las infecciones en los servicios de cuidados intensivos. 2016.

13. Rivera de la Torre, D. Programa de limpieza y desinfección en superficies hospitalarias para la prevención de infecciones relacionadas a la asistencia sanitaria. 2018. 